\title{
Pushing the boundaries of laparoscopic myomectomy: a comparative analysis of peri-operative outcomes in 323 women undergoing laparoscopic myomectomy in a tertiary referral centre
}

\author{
Rebecca Mallick* (1) and Funlayo Odejinmi
}

\begin{abstract}
Background: The aim of this study was to analyse the demographic data and peri-operative outcomes of women undergoing a laparoscopic myomectomy and assess what factors, if any, precluded using the laparoscopic approach.

Methods: A single surgeon observational study of 323 patients undergoing a laparoscopic myomectomy was undertaken. Data was collected prospectively over a 12-year period and analysed using SPSS. Surgical outcomes included operating time, estimated blood loss, conversion to laparotomy, intraoperative and postoperative complications and duration of inpatient stay.

Results: A total of 323 patients underwent a laparoscopic myomectomy over the 12-year period. The majority of fibroids removed were intramural (49\%) and subserosal (33\%). The mean size of fibroids removed was $7.66 \pm 2.83(7.34-7.99) \mathrm{cm}$, and the mean number was $4 \pm 3.62$ (3.6-4.39), with the greatest being 22 removed from a single patient. Average blood loss was $279.14 \pm 221.10(254.59-303.69) \mathrm{ml}$ with mean duration of surgery and inpatient stay recorded as $112.92 \pm 43.21$ (107.94-117.91) $\mathrm{min}$ and $1.88 \pm 0.95$ (1.77-1.99) days, respectively. No major intraoperative complications were noted, and the conversion to laparotomy rate was $0.62 \%$. All histology following morcellation was benign. Over the 12-year period despite increasingly large and more numerous fibroids being tackled, increasing experience resulted in a simultaneous reduction in overall blood loss, operating time and duration of inpatient stay.

Conclusions: Laparoscopic myomectomy is a safe and efficacious procedure that should be considered the gold standard surgical treatment option for fibroids. With experience, the procedure can be undertaken with minimal complications, a low risk of conversion to laparotomy and early discharge from hospital, even in cases of large and multiple fibroids that historically would have required the open approach. This allows even the most complex of cases to now benefit for the advantages of the minimal access approach.
\end{abstract}

Keywords: Laparoscopic myomectomy, Outcomes, Complications

\footnotetext{
* Correspondence: rmallick@doctors.org.uk

Department of Gynaecology, Barts Health NHS Trust, Whipps Cross University Hospital, London E11 1NR, UK
} 


\section{Background}

Uterine fibroids remain the commonest benign tumour encountered in the female population. They affect around $20-25 \%$ of women with symptoms ranging from heavy menstrual bleeding and pressure to subfertility. The clinical features and treatment options offered are largely dependent on the type, number and position of the fibroids, and historically, the surgical treatment of choice was an open myomectomy or abdominal hysterectomy. However, many women, especially those of reproductive age, prefer more conservative uterine-preserving techniques, and the minimal access route offers significant benefits both in terms of recovery and future fertility [1-3]. These benefits are now well established in the wider literature, and the minimal access route should generally be considered the gold standard surgical treatment for such women. But is there a limit to what can be performed laparoscopically and what are the risks? Are there specific demographic features that can affect the surgical outcome and can help guide us when counselling patients and choosing the safest surgical procedure? Since the first laparoscopic myomectomy, described by Kurt Semm in 1979 [4], there have been significant technological advances and increasing expertise in minimal access surgery and the previously considered contra-indications to laparoscopic myomectomy [5, 6] may no longer exist in experienced hands. The aims of this study were to analyse the demographic data and perioperative outcomes of 323 women who underwent a laparoscopic myomectomy over a 12 -year period in a tertiary referral centre in London and compare our findings to the published literature.

\section{Methods}

This is a prospective observational study of 323 patients who underwent a laparoscopic myomectomy from March 2004 to November 2016. All patients were operated on by a single surgeon at Whipps Cross University Hospital Trust. The only exclusion criteria was uterine size greater than 28 weeks size limiting access to the pelvis. A standardised technique was used; initial entry was through an intra-umbilical incision or palmer's point in cases where the uterine size was more than 14 weeks, with two $5 \mathrm{~mm}$ ancillary lateral ports and a suprapubic port. For haemostasis, $800 \mu \mathrm{g}$ misoprostol was administered rectally and vasopressin injected intra-myometrially unless contraindicated. For uterine manipulation, a ClearView ${ }^{\text {тм }}$ (Clinical Innovations) uterine manipulator was used to achieve the optimum uterine position. For most cases, the Harmonic $^{\text {тм }}$ (Ethicon) scalpel was used, but more recently, alternative ultrasonic energy devices such as Thunderbeat $^{\mathrm{Tm}}$ (Olympus) have been introduced. A $5 \mathrm{~mm}$ myoma screw and grasping forceps were used for traction and counter traction. Initially, the resulting defects were closed in two or three layers as required using polyglactin sutures for the myometrium and monofilament sutures used for the serosa; however, more recently, self-retaining sutures such as $\mathrm{V}-\operatorname{loc}^{\mathrm{TM}}$ (Covidien) and Stratafix ${ }^{\mathrm{TM}}$ (Ethicon) have been introduced. For adhesion prevention, due to the discontinuation of Sprayshield ${ }^{\mathrm{TM}}$ (Covidien), Interceed ${ }^{\mathrm{TM}}$ (Ethicon) has been used since 2014. Myomas were removed by electro-mechanical morcellation through the suprapubic port, currently without the use of containment/morcellation bags, and sent for histology. Initially, we used the Johnson and Johnson Ethicon morcellator; however, when it was withdrawn, we changed to the RotoCut morcellator (Stortz), and more recently, we have been using the LiNA morcellator.

All patients were assessed for suitability pre-operatively and had radiological fibroid mapping using either ultrasound or MRI. Patients were given written information regarding their procedure and counselled preoperatively about their recovery and anticipated discharged within $24 \mathrm{~h}$. Also, following the concerns regarding the possibility of dissemination of malignant cells during the morcellation process [7], we considered the information provided by national and international societies $[8,9]$ and devised a leaflet explaining the risks of morcellation. This leaflet contained not only information about the potential risk of dissemination of malignancy and the risk of upstaging a leiomyosarcoma, but also the possible risks of visceral injury. All patients were also given antibiotics prophylaxis at induction of anaesthesia and appropriate thromboprophylaxis.

Patient demographics (age, BMI, parity), procedure details and patient outcomes were collected prospectively from 2004 onwards on an Excel spreadsheet and entered immediately following each procedure and on discharge from hospital. The data was analysed using SPSS (version 22 ). The $t$ test was used for the comparison group analysis, but if the data failed the homogeneity assumption (Levene's test), a Mann-Whitney test was undertaken. A $p$ value of 0.05 was considered significant. Formal ethical approval was not required as this was an evaluation of ongoing surgical practice.

\section{Results}

Three hundred twenty-three patients underwent a laparoscopic myomectomy over the 12-year period. There was almost a fivefold increase in the number of laparoscopic myomectomies performed in 2016 compared to 2004 (Fig. 1). Patient demographics are summarised in Table 1. $40.3 \%$ had undergone previous abdominal surgery with $27.6 \%$ undergoing a previous laparoscopic procedure and $12.7 \%$ undergoing a laparotomy.

A total of 1921 fibroids were removed with the size of the dominant fibroid ranging from 2 to $20 \mathrm{~cm}$ (mean $7.6 \mathrm{~cm})$. The majority of fibroids removed were intramural (49\%) and subserosal (33\%) and less frequently submucosal (17\%) and pedunclulated (1\%). With regards 


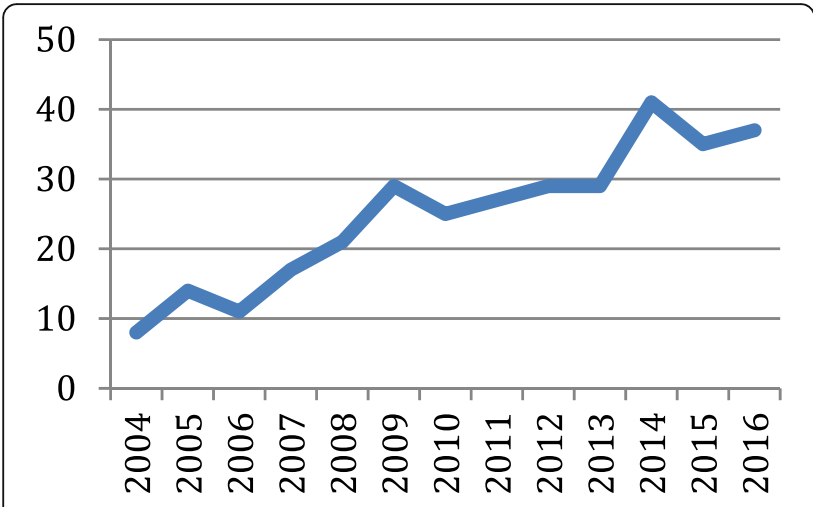

Fig. 1 Laparoscopic myomectomies per year

to the position of the fibroids, the majority were posterior (40\%), fundal (25\%) and anterior (20\%) with less common sites including broad ligament $(9 \%)$, lateral (3\%) and cervical (3\%). Thirty-one percent of patients had a single fibroid removed, and the remaining $69 \%$ required multiple fibroid removal. The mean number of fibroids removed was 4, with the greatest being 22 removed from a single patient. Average blood loss was $279.14 \mathrm{ml}$ with mean duration of surgery and inpatient stay recorded as $112.92 \mathrm{~min}$ and 1.88 days, respectively. Operative features are summarised in Table 2.

Twenty-three percent of patients had co-existing endometriosis, which was excised.

No major intraoperative complications were noted. Two procedures were converted to a mini laparotomy, one due to technical difficulties in closing the uterine incision and the other due to anaesthetic concerns with the patient's ventilation, giving a conversion rate of $0.62 \%$. Nine patients required post-operative blood transfusions (2.79\%). Seven patients had documented post-operative complications (2.17\%); one patient returned to theatre on day 2 due to intra-abdominal bleeding, which was managed by a

Table 1 Patient demographics

\begin{tabular}{ll}
\hline Variable & Value \\
\hline Age (years) & $38(24-56)$ \\
BMI & $26.5(16-46)$ \\
Parity & $0(0-6)$ \\
Ethnicity & \\
$\quad$ African/Afro-Caribbean & $196(60.7 \%)$ \\
$\quad$ Asian & $43(13.3 \%)$ \\
$\quad$ Caucasian & $84(26 \%)$ \\
Indications for surgery & \\
$\quad$ Bleeding & $179(55.2 \%)$ \\
$\quad$ Pain/pressure & $77(23.8 \%)$ \\
Infertility & $68(21 \%)$ \\
\hline
\end{tabular}

Data presented as median (range) or absolute number (\%)
Table 2 Operative features

\begin{tabular}{ll}
\hline Variable & Value \\
\hline Largest fibroid removed (cm) & $7.66 \pm 0.165(7.34-7.99)$ \\
Number of fibroids removed & $4 \pm 0.202(3.6-4.39)$ \\
Weight of fibroids removed $(\mathrm{g})$ & $216.28 \pm 12.127(192.42-240.14)$ \\
Blood loss (ml) & $279.14 \pm 12.477(254.59-303.69)$ \\
Duration of surgery (min) & $112.92 \pm 2.533(107.94-117.91)$ \\
Inpatient stay duration (days) & $1.88 \pm 0.055(1.77-1.99)$
\end{tabular}

Data presented as mean \pm standard error of mean $(95 \% \mathrm{Cl})$

laparotomy and re-suturing. Two patients had postoperative urinary retention, and four patients developed port site hernias.

All specimens were removed using electo-mechanical morcellation, and in all cases, the histology was reported as benign. There were histological variants described and these included apoplectic myoma, adenomatoid tumour and symplastic tumour. These tumours are also benign and do not need any follow-up; however, one of the patients, who had an atypical myoma, opted for a laparoscopic hysterectomy and required no further treatment.

Between the onset of the study to January 2010, out of the $41 \%$ of patients who had surgery for infertility, $56 \%$ had conceived after surgery.

When comparing the number of fibroids removed and operative outcomes, there was a significantly greater blood loss and operating time in patients having multiple fibroids removed compared to those having a single myomectomy.

Fibroids over $9 \mathrm{~cm}$ also had a significantly greater blood loss and operating time when compared to those less than $8 \mathrm{~cm}$. Both age and BMI did not appear to have any significant impact on operative outcomes (Table 3).

\section{Learning curve of laparoscopic myomectomy}

Over the time 12-year period, the cases have become increasingly complex with larger fibroids and more numerous fibroids being tackled in women who are increasingly more obese (Fig. 2). Despite this, the increasing experience and expertise has resulted in a simultaneous reduction in blood loss and operating time (Fig. 3). Inpatient stay has been also reduced by more than half from a mean of 3.5 days to 1.3 days.

\section{Discussion}

Since the first laparoscopic myomectomy in 1979, there has been a wealth of data published highlighting the benefits of the minimal access approach over the standard open approach. Benefits include reduced blood loss, shorter hospital stay, reduced post-operative pain and less adhesion formation, and many case series have been published worldwide [10-25] (Table 4). However, this series appears to one of the largest and the only prospective single surgeon series from the UK. 
Table 3 Fibroid and patient factors impacting operative outcomes

\begin{tabular}{|c|c|c|c|}
\hline & $\begin{array}{l}\text { Single } \\
\text { myomectomy }\end{array}$ & $\begin{array}{l}\text { Multiple } \\
\text { myomectomy }\end{array}$ & $p$ value \\
\hline Blood loss (ml) & 218.5 & 308.45 & 0.001 \\
\hline Operating time (min) & 85.6 & 125.43 & $<0.001$ \\
\hline \multirow[t]{2}{*}{ Inpatient stay (days) } & 1.81 & 1.9 & 0.437 \\
\hline & Fibroid $<8 \mathrm{~cm}$ & Fibroid $\geq 9 \mathrm{~cm}$ & $p$ value \\
\hline Blood loss (ml) & 121.34 & 192.03 & $<0.001$ \\
\hline Operating time (min) & 105.30 & 130.12 & $<0.001$ \\
\hline \multirow[t]{2}{*}{ Inpatient stay (days) } & 1.799 & 1.989 & 0.127 \\
\hline & $\mathrm{BMI}<29.9$ & $\mathrm{BMI}>30$ & $p$ value \\
\hline Blood loss (ml) & 272 & 278 & 0.837 \\
\hline Operating time (min) & 112 & 114 & 0.765 \\
\hline \multirow[t]{2}{*}{ Inpatient stay (days) } & 1.85 & 1.64 & 0.062 \\
\hline & Age $<40$ & Age $\geq 40$ & $p$ value \\
\hline Blood loss (ml) & 259 & 193 & 0.059 \\
\hline Operating time (min) & 114 & 94 & 0.054 \\
\hline Inpatient stay (days) & 1.9 & 1.7 & 0.408 \\
\hline
\end{tabular}

Historically, the laparoscopic route had been reserved for smaller and less numerous fibroids due to the advanced technical skills required, and many recommendations have been made in the literature as to the "safe" limits of laparoscopic surgery. In 1996, Dubuisson et al. [10] advised that laparoscopic myomectomy should only be considered when the fibroids are less than $8 \mathrm{~cm}$ and in cases where there are less than two fibroids to be removed due to the high conversion to laparotomy rates. Other authors have suggested that the presence of more than four large fibroids greater than $4 \mathrm{~cm}$ in diameter or a solitary fibroid greater than $10 \mathrm{~cm}$ in diameter should be a contraindication to the laparoscopic approach $[26,27]$.

More recently, due to technological advances and increasing surgical expertise, these traditional boundaries are being pushed and larger. Sinha et al. [19] published a case series in 2008 assessing myomectomies for fibroids greater than $10 \mathrm{~cm}$ in size and five in number. Our case series has an average fibroid size of $8 \mathrm{~cm}$ (range 2-20 cm), and the average number of fibroids removed was four (range 1-22), which is greater than the traditional limits and larger than the vast majority of published case series (Table 3). However, our complication rate remains low (2.17\%) in keeping with other case series including those historical studies using more conservative limits $[10,17,21]$. To date, the largest laparoscopic myomectomy case series was described by Sizzi et al. [18] in 2007, which described a similarly low complication rate of $2.02 \%$ in 2050 cases, although in this case series, both the number $($ mean $=2.26)$ and size of fibroids $($ mean $=6.40)$ removed were significantly less than ours.

Historically, one of the most common complications encountered during a laparoscopic myomectomy was the need to convert to laparotomy. In one of the earliest case series, Dubusisson et al. [10] reported a conversion rate of $7.5 \%$ and attributed this to fibroid size, number and position. Furthermore in 2001, Dessolle et al. [11] reported a similarly high conversion rate of $14.8 \%$. Over the last 10 years, with increasing experience and expertise, this has significantly dropped to reported rates in the literature of between 0 and $1.69 \%$ [15, 21, 22, 25]. We also report a low conversion to laparotomy rate of $0.62 \%$. Reassuringly, however, our conversion rate remained low despite tackling larger and more numerous fibroids.

In our case series, the mean blood loss was $279 \mathrm{ml}$, which was comparable to the wider literature [17, 20, 21]. Nine patients required post-operative blood transfusions; however, in the majority of these cases (77\%), the patients were anaemic pre-operatively and the need for transfusion was not directly related to operative blood loss. Maintaining haemostasis and bloodless enucleation are fundamental steps in a successful laparoscopic myomectomy, and a Cochrane review found a reduction in blood loss with the use of both misoprostol and vasopressin [28]. All the patients in our

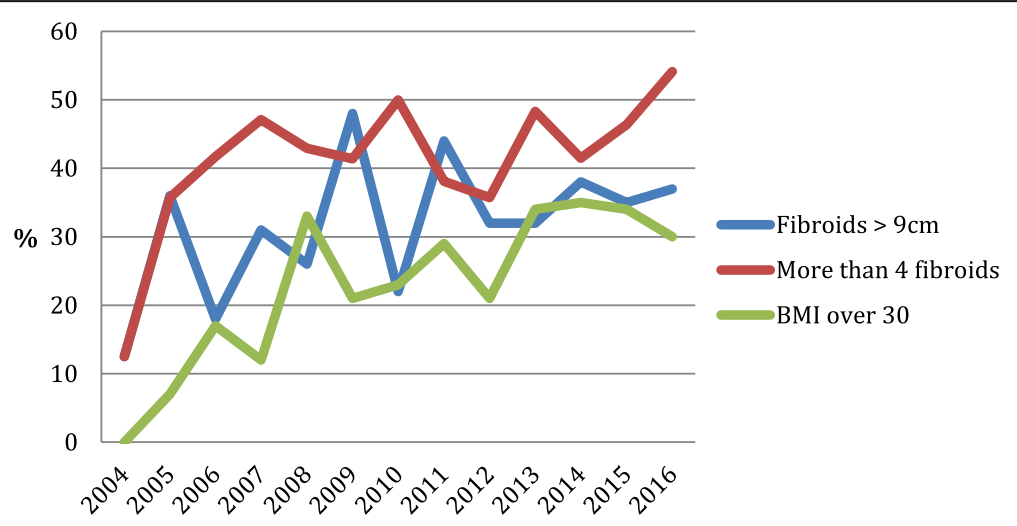

Fig. 2 Percentage of patients with fibroids size $>9 \mathrm{~cm}$, greater than four fibroids and a BMI over 30 over time 


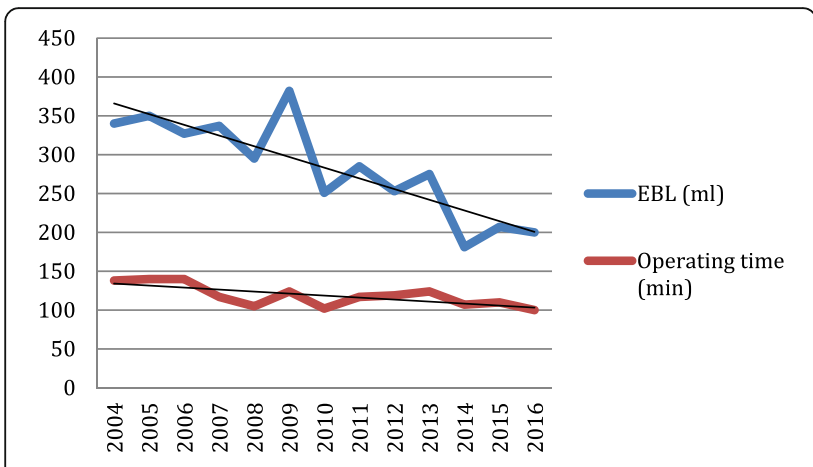

Fig. $3 \mathrm{EBL}(\mathrm{ml})$ and operating time (min) over time

series were given both misoprostol $800 \mu \mathrm{g}$ per rectum and intra-myometrial vasopressin, which helped reduce blood loss without any significant side effects.

The operating time in our case series was in keeping with the wider literature [17-19], and as one would expect, the greater the number and larger the size of fibroids, the longer the operating time, which is keeping with the findings of Sinha et al. [19]; however, this did not appear to have any significant effect on patient recovery/duration of inpatient stay. We have also found that using barbed sutures $\left(\mathrm{V}-\operatorname{loc}^{\mathrm{Tw}}\right.$ or Stratafix $\left.{ }^{\mathrm{Tm}}\right)$ has helped reduce operating time, and in a recent multicenter study, the use of such barbed sutures has also been shown to significantly reduce operative blood loss [29].

The average duration of hospital stay (1.8 days) was comparable with other studies $[18,20,21]$. Sinha et al. [19] found that hospital stay increased with increasing number, size and weight of fibroids. However, our study reassuringly found no significant effect on the day of discharge in patients with large $(>9 \mathrm{~cm})$ and numerous $(>4)$ fibroids. The reasons for this may be multifactorial, but a large factor is our extensive pre-operative counselling and well-established enhanced recovery practices.

One of the current controversies surrounding laparoscopic myomectomy is morcellation and the risk of undiagnosed sarcoma, and in April 2014, the FDA discouraged the use of electro-morcellation [7]. However, the most recent BSGE statement acknowledges the place of power

Table 4 A comparative analysis of case series of laparoscopic myomectomy from 1996 to 2017

\begin{tabular}{|c|c|c|c|c|c|c|c|c|}
\hline & $n=$ & $\begin{array}{l}\text { Fibroids } \\
\text { removed }(n)\end{array}$ & $\begin{array}{l}\text { Largest fibroid } \\
\text { removed }(\mathrm{cm})\end{array}$ & EBL (ml) & $\begin{array}{l}\text { Operating time } \\
\text { (min) }\end{array}$ & $\begin{array}{l}\text { Inpatient stay } \\
\text { (days) }\end{array}$ & $\begin{array}{l}\text { Conversion } \\
\text { rate (\%) }\end{array}$ & $\begin{array}{l}\text { Complication } \\
\text { rate }(\%)\end{array}$ \\
\hline $\begin{array}{l}\text { Dubisson } 1996 \\
\text { [10] }\end{array}$ & 213 & & & & & & 7.5 & 3.8 \\
\hline $\begin{array}{l}\text { Dessolle } 2001 \\
{[11]}\end{array}$ & 88 & $1.7 \pm 0.6(1-4)$ & $6.2 \pm 1.8(3-11$ & & $150 \pm 60(60-300)$ & $3.0 \pm 1(1-10)$ & 14.8 & \\
\hline Landi 2001 [12] & 368 & & & & $100.78 \pm 43.83$ & $2.89 \pm 1.3$ & & \\
\hline $\begin{array}{l}\text { Malzoni } 2003 \\
\text { [13] }\end{array}$ & 144 & & $7.8(5-18)$ & & $95(58-180)$ & $2.6(2-5)$ & 1.39 & \\
\hline $\begin{array}{l}\text { Malzoni } 2006 \\
\text { [16] }\end{array}$ & 982 & $2.23(1-8)$ & $\begin{array}{l}6.72 \pm 2.71(1- \\
20)\end{array}$ & & $104.5(30-360)$ & $2.02 \pm 0.61$ & 1.29 & \\
\hline $\begin{array}{l}\text { Rosetti } 2007 \\
{[24]}\end{array}$ & 332 & $2.23 \pm 1.7(1-8)$ & $6.2 \pm 2.7(1-20)$ & & $124.021 \pm 52.2$ & $2.0 \pm 0.57$ & 1.51 & \\
\hline $\begin{array}{l}\text { Yoon } 2007 \\
{[15]}\end{array}$ & 51 & $2.2 \pm 1.8$ & $9.3 \pm 1.8$ & & $85.6 \pm 38.9$ & $3.2 \pm 0.9$ & 0 & \\
\hline $\begin{array}{l}\text { Sizzi } 2007 \\
{[18]}\end{array}$ & 2050 & $2.26 \pm 1.8(1-15)$ & $\begin{array}{l}6.40 \pm 2.6(1- \\
20)\end{array}$ & & $107.71 \pm 43.42$ & $1.99 \pm 0.9$ & & 2.02 \\
\hline $\begin{array}{l}\text { Sinha } 2008 \\
{[19]}\end{array}$ & 505 & $1.85 \pm 5.706$ & $5.86 \pm 3.3$ & $90(40-2000)$ & $60(30-270)$ & & & \\
\hline $\begin{array}{l}\text { Paul } 2010 \\
{[21]}\end{array}$ & 1001 & $1.97(1-17)$ & $(1-20)$ & $248(20-1000)$ & $93(20-280)$ & $1.5(1-5)$ & 0.1 & 2.62 \\
\hline $\begin{array}{l}\text { Tinelli } 2012 \\
{[25]}\end{array}$ & 235 & & $6.6 \pm 3.5(4-10)$ & $118 \pm 27.9$ & $84(25-126)$ & & 0 & \\
\hline Sankaran 2013 [22] & 125 & $3.69 \pm 2.96(1-15)$ & $\begin{array}{l}7.68 \pm 2.95(2- \\
15)\end{array}$ & $\begin{array}{l}339.83 \pm 254.15(50- \\
1500)\end{array}$ & $\begin{array}{l}115.9 \pm 42.09(40- \\
200)\end{array}$ & $\begin{array}{l}2.38 \pm 1.09(1- \\
7)\end{array}$ & 1.69 & \\
\hline Saccardi 2014 [23] & 444 & & $7.6 \pm 2.7$ & $184.1 \pm 233.5$ & $77.2 \pm 33$ & $2.54 \pm 1.1$ & & \\
\hline $\begin{array}{l}\text { Sandberg } 2016 \\
\text { [20] }\end{array}$ & 731 & $3.54 \pm 4.10$ & & $181.54 \pm 342.02$ & & $0.58 \pm 1.00$ & 1.09 & \\
\hline $\begin{array}{l}\text { Bean } 2017 \\
{[17]}\end{array}$ & 514 & $1(1-12)$ & $7(1-20)$ & $73(5-3000)$ & & $2(0-24)$ & 0.4 & 3.5 \\
\hline
\end{tabular}

Data presented as mean \pm SD (range) or $\%$ 
morcellation and the benefits of laparoscopic myomectomy and highlights the importance of patient counselling regarding the potential risks although low [8]. Reassuringly, all the histology reported in our case series was benign. However, caution must be applied in the older age group, and to avoid the risk of undiagnosed malignancy patient selection and counselling is key. Red flag symptoms that should raise suspicion include new onset irregular or heavy vaginal bleeding, unexplained weight loss and systemic symptoms. None of the patients in this series were menopausal, and we would also not routinely offer laparoscopic myomectomy to peri-menopausal women; however, many prefer uterine conserving techniques and decline hysterectomy. In such women, detailed counselling is essential not only with regard to the potential up-staging of malignancy if they were found to have a sarcoma, but also with regard to the potential operative benefits of hysterectomy over myomectomy such as reduced blood loss, operating time and hospital stay as highlighted by Odejinmi et al. [30] when comparing myomectomy and hysterectomy in the older age group. An alternative approach is to use a morcellation bag, which contains the theoretical risk of spreading malignancy if present [31]. This practice is becoming increasingly popular, but national guidance is yet to recommend its general use. Consideration should also be given to the implementation of a national database to record outcomes following laparoscopic myomectomy and morcellation; this would also help with the counselling process and assessment of individual risk.

\section{Conclusions}

In conclusion, our study highlights that in experienced hands, laparoscopic myomectomy is a safe and efficacious procedure with low complication and conversion to laparotomy rates even when large $(>8 \mathrm{~cm})$ and numerous $(>4)$ fibroids are tackled, unlike the earlier studies in the wider literature. As expected, blood loss and operating time are directly related to fibroid size and number; however, large, multiple fibroids can be tackled safely without any increase in patient morbidity and length of hospital stay. Experience, ongoing self-audit of outcomes and a dedicated enhanced recovery approach are essential to the improved outcomes demonstrated in this study.

\section{Acknowledgements}

Nothing to declare.

Funding

No specific funding was required.

Availability of data and materials

Data supporting our findings can be found by contacting the corresponding author.

\section{Authors' contributions}

FO devised the project and participated in data collection and manuscript writing. RM participated in the project development, data analysis and manuscript writing. Both authors approved the final manuscript.

Ethics approval and consent to participate

The study was discussed with the local research and ethics committee, and ethical approval was not required.

Consent for publication

Not applicable.

Competing interests

The authors declare that they have no competing interests.

\section{Publisher's Note}

Springer Nature remains neutral with regard to jurisdictional claims in published maps and institutional affiliations.

Received: 16 August 2017 Accepted: 1 November 2017

Published online: 13 November 2017

References

1. Peacock K, Hurst BS (2006) Laparoscopic myomectomy. Surg Technol Int. 15:141-145

2. Bhave Chittawar P, Franik S, Pouwer AW, Farquhar C (2014) Minimally invasive surgical techniques versus open myomectomy for uterine fibroids. Cochrane Database Syst Rev 21(10):CD004638

3. Takeuchi H, Kinoshita K (2002) Evaluation of adhesion formation after laparoscopic myomectomy by systematic second-look microlaparoscopy. J Am Assoc Gynecol Laparosc. 9(4):442-446

4. Semm K (1979) New methods of pelviscopy (gynecologic laparoscopy) for myomectomy, ovariectomy, tubectomy and adnectomy. Endoscopy 11(2): 85-93

5. Dubuisso JB, Fauconnier A, Babaki-Fard K, Chapron C (2000) Laparoscopic myomectomy: a current view. Hum Reprod Update 6(6):588-594

6. Glasser MH (2005) Minilaparotomy myomectomy: a minimally invasive alternative for the large fibroid uterus. J Minim Invasive Gynecol 12(3): 275-283

7. FDA. UPDATED Laparoscopic uterine power morcellation in hysterectomy and myomectomy: FDA safety communication (https://wayback.archive-it.org/7993/ 20161023125535/, http://www.fda.gov/NewsEvents/Newsroom/ PressAnnouncements/ucm393689.htm). Accessed 1 Jan 2017

8. BSGE. BSGE STATEMENT ON POWER MORCELLATION https://bsge.org.uk/ news/bsge-statement-power-morcellation/. Accessed 1 Jan 2017

9. Brölmann H, Tanos V, Grimbizis G, Ind T, Philips K, van den Bosch T et al (2015) Options on fibroid morcellation: a literature review. Gynecol Surg 12(1):3-15

10. Dubuisson J-B, Chapron C, Levy L (1996) Difficulties and complications of laparoscopic myomectomy. J Gynecol Surg 12(3):159-165

11. Dessolle L, Soriano D, Poncelet C, Benifla JL, Madelenat P, Darai E (2001) Determinants of pregnancy rate and obstetric outcome after laparoscopic myomectomy for infertility. Fertil Steril 76(2):370-374

12. Landi S, Zaccoletti R, Ferrari L, Minelli L (2001) Laparoscopic myomectomy: technique, complications, and ultrasound scan evaluations. J Am Assoc Gynecol Laparosc 8(2):231-240

13. Malzoni M, Rotond M, Perone C, Labriola D, Ammaturo F, Izzo A et al (2003) Fertility after laparoscopic myomectomy of large uterine myomas: operative technique and preliminary results. Eur J Gynaecol Oncol 24(1):79-82

14. Marret $\mathrm{H}$, Chevillot M, Giraudeau B (2004) A retrospective multicentre study comparing myomectomy by laparoscopy and laparotomy in current surgical practice. What are the best patient selection criteria? Eur J Obstet Gynecol Reprod Biol 117(1):82-86

15. Yoon HJ, Kyung MS, Jung US, Choi JS (2007) Laparoscopic myomectomy for large myomas. J Korean Med Sci 22(4):706-712

16. Malzoni M, Sizzi O, Rossetti A, Imperato F (2006) Laparoscopic myomectomy: a report of 982 procedures. Surg Technol Int 15:123-129

17. Bean EMR, Cutner A, Holland T, Vashisht A, Jurkovic D, Saridogan E (2017) Laparoscopic myomectomy: a single-center retrospective review of 514 patients. J Minim Invasive Gynecol 24(3):485-493 
18. Sizzi O, Rossetti A, Malzoni M, Minelli L, La Grotta F, Soranna L et al (2007) Italian multicenter study on complications of laparoscopic myomectomy. J Minim Invasive Gynecol 14(4):453-462

19. Sinha R, Hegde A, Mahajan C, Dubey N, Sundaram M (2008) Laparoscopic myomectomy: do size, number, and location of the myomas form limiting factors for laparoscopic myomectomy? J Minim Invasive Gynecol 15(3):292-300

20. Sandberg EM, Cohen SL, Jansen FW, Einarsson JI (2016) Analysis of risk factors for intraoperative conversion of laparoscopic myomectomy. J Minim Invasive Gynecol 23(3):352-357

21. Paul GP, Naik SA, Madhu KN, Thomas T (2010) Complications of laparoscopic myomectomy: a single surgeon's series of 1001 cases. Aust N Z J Obstet Gynaecol 50(4):385-390

22. Sankaran S, Odejinmi F (2013) Prospective evaluation of 125 consecutive laparoscopic myomectomies. J Obstet Gynaecol 33(6):609-612

23. Saccardi C, Gizzo S, Noventa M, Ancona E, Borghero A, Litta PS (2014) Limits and complications of laparoscopic myomectomy: which are the best predictors? A large cohort single-center experience. Arch Gynecol Obstet 290(5):951-956

24. Rossetti A, Sizzi O, Chiarotti F, Florio G (2007) Developments in techniques for laparoscopic myomectomy. Jsls 11(1):34-40

25. Tinelli A, Hurst BS, Hudelist G, Tsin DA, Stark M, Mettler L et al (2012) Laparoscopic myomectomy focusing on the myoma pseudocapsule: technical and outcome reports. Hum Reprod 27(2):427-435

26. Ribeiro SC, Reich H, Rosenberg J, Guglielminetti E, Vidali A (1999) Laparoscopic myomectomy and pregnancy outcome in infertile patients. Fertil Steril 71(3):571-574

27. Marret H, Chevillot M, Giraudeau B (2006) Factors influencing laparoconversions during the learning curve of laparoscopic myomectomy. Acta Obstet Gynecol Scand 85(3):324-329

28. Kongnyuy EJ, Wiysonge CS (2014) Interventions to reduce haemorrhage during myomectomy for fibroids. Cochrane Database Syst Rev 15(8):CD005355

29. Tinelli R, Litta P, Angioni S, Bettocchi S, Fusco A, Leo L et al (2016) A multicenter study comparing surgical outcomes and ultrasonographic evaluation of scarring after laparoscopic myomectomy with conventional versus barbed sutures. Int J Gynaecol Obstet 134(1):18-21

30. Odejinmi F. Maclaran K, Agarwal N (2015) Laparoscopic treatment of uterine fibroids: a comparison of peri-operative outcomes in laparoscopic hysterectomy and myomectomy. Arch Gynecol Obstet 291(3):579-584

31. Cohen SL, Einarsson Jl, Wang KC, Brown D, Boruta D, Scheib SA et al (2014) Contained power morcellation within an insufflated isolation bag. Obstet Gynecol 124(3):491-497

\section{Submit your manuscript to a SpringerOpen ${ }^{\circ}$ journal and benefit from:}

- Convenient online submission

- Rigorous peer review

- Open access: articles freely available online

- High visibility within the field

- Retaining the copyright to your article 